\title{
Emission Characteristics of Volatile Organic Compounds from Typical Coal Utilization Sources: A Case Study in Shanxi of Northern China
}

\author{
Yang $\mathrm{Xu}^{1,2^{\dagger}}$, Hualong $\mathrm{Yu}^{1 \dagger}$, Yulong $\mathrm{Yan}^{1^{*}}$, Lin Peng ${ }^{1}$, Rumei $\mathrm{Li}^{1,2}$, Cheng Wang ${ }^{1,2}$, \\ Zhiyong $\mathrm{Li}^{3}$
}

${ }^{1}$ MOE Key Laboratory of Resources and Environmental System Optimization, College of Environmental Science and Engineering, North China Electric Power University, Beijing 102206, China

${ }^{2}$ School for Energy, Power and Mechanical Engineering, North China Electric Power University, Beijing 102206, China

${ }^{3}$ School of Environmental Science and Engineering, North China Electric Power University, Baoding 07100, China

\section{ABSTRACT}

China, where coal is the dominant energy resource, accounted for $50.5 \%$ of the world's coal consumption-or 1906.7 million tons of oil equivalent-during 2018. As a major source of volatile organic compounds (VOCs), coal utilization also led to high national emissions of these pollutants. In this study, we investigated the profiles; benzene, toluene, ethylbenzene, and xylene (BTEX) ratios; ozone formation potential (OFP); and secondary organic aerosol (SOA) formation potential of VOCs generated by coal-utilizing steel plants, power plants, coking plants, and residential stoves in northern China. Among the detected VOCs, the results identified 1-butene as the most abundant species for both the power plants (36.7\%) and the residential stoves $(41.7 \%)$ as well as a significant contributor at the steel plants (7.3\%), and alkenes, alkanes, and aromatics composed the largest groups for the power plants (42.0\%) and residential stoves $(60.2 \%)$; steel plants (59.2\%); and coking plants (66.1\%), respectively. Additionally, the VOC profiles for power plants employing the same coal source or combustion technology exhibited strong similarities, although the BTEX ratios varied more between plants using different coal sources than those using different combustion technologies. Finally, alkenes were primarily responsible for the ozone formation (73.1\%, 59.0\%, and $87.6 \%$ for the power plants, steel plants, and residential stoves, respectively), whereas aromatics were primarily responsible for the SOA formation (more than $94.0 \%$ for all four coal-utilizing sources).

* Corresponding Author:

yanyulong@ncepu.edu.cn

${ }^{\dagger}$ These authors contributed equally to this work

Keywords: Volatile organic compounds, Source profiles, BTEX, Ozone formation potential, Coal utilization source

\section{Publisher:}

Taiwan Association for Aerosol Research

ISSN: $1680-8584$ print

ISSN: 2071-1409 online

Copyright: The Author(s). This is an open access article distributed under the terms of the Creative Commons Attribution License (CC BY 4.0), which permits unrestricted use, distribution, and reproduction in any medium, provided the original author and source are cited.

\section{INTRODUCTION}

The tropospheric ozone concentration in China has continually increased in recent years. Compared to 2018, the average concentrations of $\mathrm{PM}_{2.5}, \mathrm{PM}_{10}, \mathrm{SO}_{2}, \mathrm{NO}_{2}$, and $\mathrm{CO}$ in 337 major cities declined in 2019 by $0 \%, 1.6 \%, 15.4 \%, 0 \%$, and $0 \%$, respectively, while only ozone concentration increased by $6.5 \%$ (Ministry of Ecological Environment, 2020). As the main precursor of ozone, VOC pollution is the main cause of serious tropospheric ozone pollution problems. Moreover, VOCs play an important role in complex atmospheric pollution formation, which is linked to the formation of peroxides, aldehyde, ketone, peroxyacyl nitrates (PANs), and SOA (Yao et al., 2006). Atmospheric VOCs can also adversely affect human health, plants, animals and the ecological environment (Zou et al., 2013). The U.S. EPA (2020) identified 389 hazardous air pollutants that 
have severe negative impacts on human health and the environment. The priority control pollutants list includes benzene series and many other VOC species because of their strong irritating, carcinogenic, and toxic effects. Therefore, controlling VOC emissions can help reduce concentration of ozone and $\mathrm{PM}_{2.5}$, decreasing photochemical smog pollution (Liu et al., 2008a) and mitigating the adverse impact of air pollution on human health.

As the largest coal producer and consumer in the world, China consumed 2.80 billion tons of standard coal in 2019 , accounting for $57.6 \%$ of the total primary energy consumption (National Bureau of Statistics, 2020). Coal consumption is one of the most important energy sources in China, and the national total coal consumption is expected to continue to increase (Dai, 2017). China's coal-dominated energy consumption is predicted to continue for at least 20 years (Liu, 2014). Power plant, steel plant, and coking plant are the key industries of national economy. The electric energy production of coal-fired power plant accounted for $64.2 \%$ of national electricity generation in 2019 (China Electricity Council, 2020). In addition, China is the largest coke and steel producer in the world (China Coking Industry Association, 2019). According to the data from the National Bureau of Statistics (2020), 95.8\% of the total coal consumption was used for industrial purposes in China, and the industries (production and supply of electric and heat power, mining and washing of coal, smelting and pressing of ferrous metals) related to coal-fired power generation, steelmaking and cokemaking accounted for $61.8 \%$ of the total coal consumption in 2018 (National Bureau of Statistics, 2019). As significant coal usage industries in China, coalfired power generation, steel, and coking industries have attracted widespread attention. In addition, coal is the main fuel for rural residential cooking and heating stoves in China. A previous study showed that there are approximately 60 million residential coal-fired heating stoves in rural China (Wang et al., 2016). However, due to its direct combustion mode, exhaust mode operations, low combustion efficiency, lack of stack gas dedusting and desulfurization equipment (Tsai et al., 2003; Zhang and Smith, 2007; Wang et al., 2016), the flue gas pollution produced by residential coal usage is one of the main sources of winter haze in northern China, which also poses a serious indoor threat to the health of rural residents (Liu et al., 2017). The VOCs produced from the coal utilization processes mentioned above are significant sources of atmospheric VOC pollution. A previous study identified coal-fired thermal power generation (Yan et al., 2016) and flue gas from coking process (Li et al., 2014) to be the main anthropogenic sources of VOCs in the northern city of China.

Many studies have analyzed the VOC emission characteristics from vehicles (Kawashima et al., 2006; Olson et al., 2009; Yao et al., 2016; Zhang et al., 2016), biomass burning (James et al., 2001; Evtyugina et al., 2013; Jumpponen et al., 2013), solvent (Niedojadlo et al., 2007; Yuan et al., 2010; Mo et al., 2015; Tian, 2015), petrochemical (Chen et al., 2006; Zhan, 2015), and refining (Cetin et al., 2003; Lin et al., 2004), but research on VOC emissions from coal utilization sources is limited. In previous studies, Fernández-Martínez et al. (2001) studied the characteristics of 16 VOC species emitted during the coal utilization process in five Spanish coal power plants and found that aromatics, aliphatic hydrocarbons, and chlorinated compounds were the main VOC species formed during coal utilization. Shi et al. (2015) analyzed the VOC emission characteristics of coalfired industry plants in Liaoning Province (northern China), and concluded that halogenated hydrocarbons were the representative VOC groups from iron smelt and coke production plants, while aromatics were the largest VOC group from heating stations. Li et al. (2018) studied the VOC emission characteristics of coal-fired coking plants, and power plants in Hebei Province (northern China), and the results showed that benzene, acetylene, and ethane were the three most abundant VOC species emitted from both power plants and coking plants. Santos et al. (2004) analyzed 36 VOC species from the stack gases of coal-fired power stations in Brazil, and found benzene to be the highest VOC species. In southern Taiwan, Tsai et al. (2008) investigated 68 VOC species emitted from four types of technology processes (including coke manufacturing, sintering, hot forming, and cold forming) in an integrated steelworks, and found that toluene, 1,2,4-trimethylbenzene, isopentane, $m, p$-xylene, 1-butene, ethylbenzene, and benzene were the dominant $\mathrm{VOC}$ species in these processes.

Scholars (Liu et al., 2008a; Mo et al., 2016; Wu and Xie, 2017) have already conducted significant research on VOC emission characteristics from different VOC emission sources and regions. Although the VOC emission characteristics of typical coal usage sources in China have been initially established, there are still many limitations and concerns regarding the accuracy of these 
VOC source profiles: The types of investigated VOC emission sources are limited and insufficient, the measurement and analysis methods of the source profiles are not unified, and species selected for VOC source profiles are not consistent. VOC source profiles represent the chemical composition of VOC species and the relative contribution of a certain source, which can be used to identify the VOC emission sources and evaluate their influence on ozone formation. Previous studies (Mo et al., 2014; Hu, 2017; Huang et al., 2020) identified significant differences between some VOC source profiles from the same industrial emission source due to various factors, such as differences in technology and raw material. Relevant research (Mo et al., 2016; Wu and Xie, 2017) also identified regional differences in VOC emission characteristics. Therefore, a systematic, standard and localized VOC source profile database is required to better understand the VOC characteristics of typical emission sources and solve current photochemical smog and ozone pollution problems. In this study, we investigated the VOC characteristics in five coal-fired power plants with different coal source usages and different coal combustion technologies. These findings have not been reported in previous studies. This study also collected VOC samples from two steel plant production stages to produce more refined VOC profiles from steel plants. We also conducted a comparative analysis of VOC profiles between four different coal utilization processes. The emission characteristics of VOCs from various coal utilization processes (coal-fired power plants, steel plants, coking plants, and residential stoves) were investigated in this study. The research objectives were to (1) conduct a comparative analysis of VOC source profiles from four types of coal utilization processes, (2) calculate BTEX ratios to identify the emission sources, (3) study the ozone formation potential of individual VOC species to investigate their influence on atmospheric ozone, and (4) estimate the SOA formation potential of VOC species emitted from coal utilization processes.

\section{METHODS}

The study area, Shanxi Province, is a typical coal consumption province in China. This province only accounts for $1.6 \%$ of China's land area but contributes approximately $11.8 \%$ of the total national coal consumption (National Bureau of Statistics, 2019). In this study, three types of industrial coal utilization processes (coking plants, steel plants, and power plants) and rural residential coal utilization processes were chosen to investigate the VOC emission characteristics in northern China.

\subsection{Basic Information}

Thermal power generation was the main electricity supply in China in 2019, accounting for $64.2 \%$ of the total electricity production, while coal-fired power plants accounted for $96.8 \%$ of the total thermal power generation (China Electricity Council, 2020). Five coal-fired power plants were selected in this study, which covered the two main types of power plant coal-burning boilers: Three power plants adopted pulverized coal-fired boiler technology, and two power plants adopted circulating fluidized bed technology (Ma et al., 2015). China is the largest steel producer and consumer in the world. In steel plants, sintering and blast furnace ironmaking emit a significant mass of pollutants, including VOCs, for coal utilization. VOC samples were collected from both sintering and blast furnace ironmaking processes to study the emission composition characteristics of the steel plant stack exhaust gas. Cokemaking is another important VOC emission source in China; therefore, the flue gas from the coke oven of coking oven plants was also collected to analyze the VOC characteristics. In this study, we also investigated the VOC emission characteristics of rural cooking and heating stoves. The unqualified coal, low combustion efficiency, lack of dedusting and desulfurization facilities of rural stoves could result in serious atmospheric VOC pollution and even indoor air pollution. Detailed information on the chosen VOC emission sources is presented in Table 1.

\subsection{Sampling Collection}

The sample sites were located in exhaust chimneys or pollutant-monitoring points. VOC samples were collected using $1 \mathrm{~L}$ Tedlar bags. The studied compound concentration should be lower than the detection limit of the method. The VOC sample was collected into the sampling 


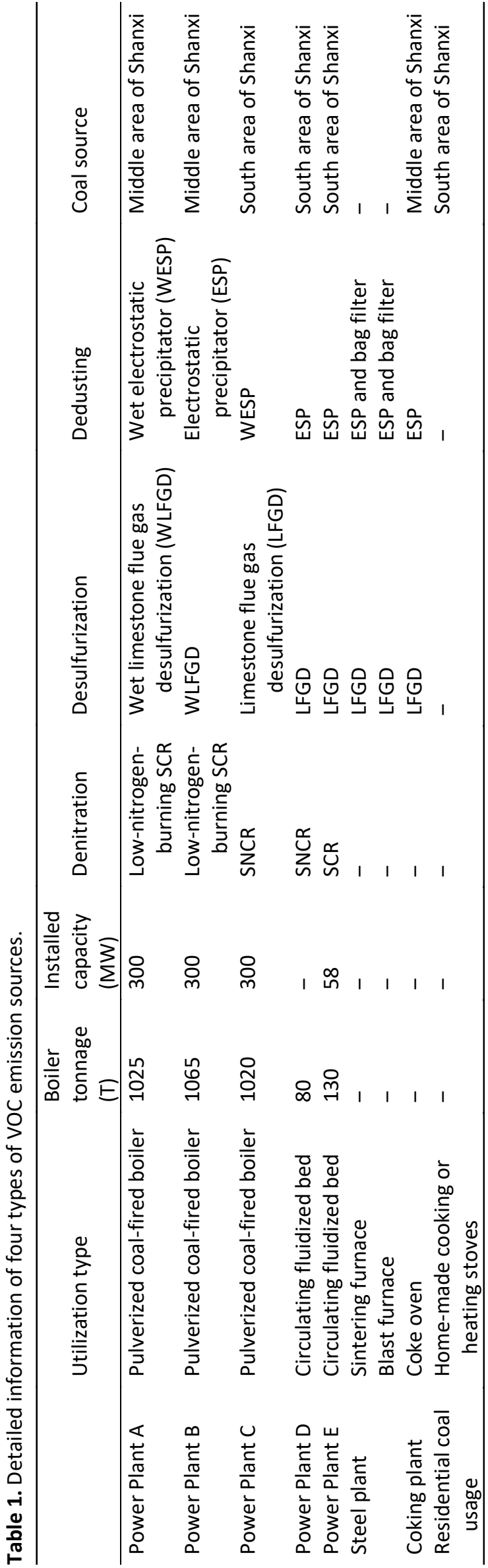

bag using a sampling pump with a flow rate of $0.5 \mathrm{~L} \mathrm{~min}^{-1}$. The joint between the pump and pipe of the Tedlar sampling bag was airtight during sampling. Close the valve and label the Tedlar bag after sampling. Relevant sampling information was recorded for the subsequent analyses. After sampling, the samples were preserved in the laboratory at room temperature and in the absence of light. All samples were analyzed within 72 hours. The detailed sampling methods are as follows.

\subsubsection{Coal-fired power plant}

The pollutant-monitoring points of exhaust chimney in power plants were chosen to be sampling sites, which were about $10 \mathrm{~m}$ from the ground. A total of 12 samples were collected in the coalfired power plants.

\subsubsection{Steel plant}

The pollutant-monitoring points of sintering and blast furnaces in steel plants were chosen to be sampling sites, which were about $15 \mathrm{~m}$ from the ground. As the water content of flue gas is relatively high in steel plants, a water absorption device was adopted for dehumidification. A total of 6 samples were collected in the steel plants.

\subsubsection{Coking plant}

The flue gas samples from air outlet of coke oven were collected in coking plant. A total of 6 samples were collected in the coking plants.

\subsubsection{Residential stove}

The flue gas samples were collected directly from the chimney of residential coal-fired heating or cooking stoves by using sampling pipe and pump. The height of sample sites was $5 \mathrm{~m}$ from ground. A total of 3 samples were collected.

\subsection{Sample Analysis}

VOC analysis was conducted using the U.S. EPA TO-15 method. The sample was analyzed by preconcentration (Model 7100; Entech Instruments) combined with Gas Chromatography-Mass Spectrometer ( 6890 GC/5973 MSD; Agilent). $300 \mathrm{~mL}$ of gas from the sample bags or canister were pumped into the preconcentrator and 
injected into the GC/MS through a preconcentration sampling system. With super-pure helium as the carrier gas, HP-VOC capillary column chromatography (film thickness of $60 \mathrm{~m} \times 0.32 \mathrm{~mm}$ $\times 1.8 \mathrm{~mm}$; Agilent) was used to isolate the compounds. The GC oven temperature was set to $40^{\circ} \mathrm{C}$, held for $2 \mathrm{~min}$, then increased to $220^{\circ} \mathrm{C}$ at a rate of $5^{\circ} \mathrm{C} \mathrm{min}^{-1}$, holding for $2 \mathrm{~min}$.

Based on electron ionization (EI), MSD runs were conducted in the scanning data acquisition mode, and the mass range was set to 35-300 amu. The method detection limit was less than $0.1 \mathrm{ppbv}$, and the repeatability was less than $10 \%$. The detected variation in the same standard sample was less than $10 \%$.

The target VOCs were identified according to retention time and standard mass spectrometry and then quantitatively analyzed using the external standard method. The standard gas mixture (1.0 ppm) was diluted with zero air and then sampled and analyzed under the same conditions as the field samples. A seven-point calibration curve (0.0, 1.0, 5.0, 10.0, 50.0, 100.0 and $200.0 \mathrm{ppbv})$ was used to quantitatively analyze the VOCs in air samples.

\subsection{Quality Assurance and Quality Control}

Before sampling, the pipe was purged with clean air to remove any impurities from the pipe surface. The pipe was inflated with the sample gas and connected to the VOC sampling device for sampling after the pipe was filled with smoke.

The pipelines of the VOC sampling system are made of Teflon materials for reducing the adsorption effect of the sampling pipe on VOC components. The sampling flowmeter was calibrated before sample collection to ensure the accuracy and stability of the flow rate.

The Tedlar sampling bags were washed at least five times before sampling. At least 1 of the 10 samples was injected with high-purity nitrogen to confirm the effectiveness of cleaning. The VOCs should be undetected or below the detection limit during the cleaning verification experiment. Before every VOC sample analysis, a blank test with high-purity nitrogen was conducted to ensure that the instrument system was not contaminated.

When drawing the standard curve, the relative standard deviation (RSD) of the response factors of each VOC species was less than $30 \%$. A total of 47 species were analyzed in this study, and "total VOCs" refers to the sum of the 47 VOCs.

\subsection{Data Analysis}

According to the target list developed by the U.S. EPA Photochemical Assessment Monitoring Stations (PAMS) program, the VOC species in this study were selected based on their reactivity to photochemical smog and tropospheric ozone formation. The OFP is related to the chemical reaction activity of VOCs in the atmosphere, and three main methods are typically used to research organic reactivity at the current level: the propylene-equivalent concentration method, $\mathrm{OH}$ radical reactivity method, and maximum increment reactivity method (MIR). The former two methods only consider the $\mathrm{OH}$ radical and $\mathrm{VOC}$ reaction rate and ignore the complicated subsequent reaction. The MIR coefficient method was selected to calculate the OFP of VOCs in this study because it is more objective with regards to the ozone formation reaction mechanism (Cheng et al., 2012). The MIR coefficient method can be used to identify VOC species with high chemical reactivity because the MIR value refers to the ozone formation ability of VOC species under optimum reactive conditions.

The OFP of 47 VOC species were calculated by Eq. (1):

$\mathrm{OFP}_{i}=\mathrm{C}_{i} \times \mathrm{MIR}_{i}$

where OFP $i$ is the ozone formation potential of VOC species $i$ ( $\mu$ g-ozone $\mathrm{m}^{-3}$ ); $\mathrm{C}_{i}$ is the mass concentration of $\mathrm{VOC}$ species $i\left(\mu \mathrm{g} \mathrm{m}^{-3}\right) ; \mathrm{MIR}_{i}$ is the corresponding maximum increment reactivity of VOC species $i$ ( $\mu \mathrm{g}$-ozone $\mathrm{m}^{-3}$ ) (Carter, 2010).

The fractional aerosol coefficient (FAC) was used to calculate the potential formation of SOA of VOCs. The SOA formation potential of 18 VOC species were calculated by Eq. (2):

$\mathrm{SOA}_{\mathrm{p}}=\mathrm{VOC}_{0} \times \mathrm{FAC}$

where $\mathrm{SOA}_{p}$ is the SOA formation potential of VOC species $\left(\mu \mathrm{g} \mathrm{m}^{-3}\right)$; VOC $\mathrm{C}_{0}$ is the initial mass 
concentration or emissions of VOC species $\left(\mu \mathrm{g} \mathrm{m}^{-3}\right)$; FAC is the corresponding fractional aerosol coefficient of VOC species (Grosjean, 1992; Lv et al., 2009).

\section{RESULTS AND DISCUSSION}

\subsection{VOCs Emission Characteristics and Source Profiles}

The 47 VOC species were classified into four groups, including 26 alkanes, 10 alkenes, 10 aromatics, and 1 alkyne. As this study focused on the VOC source profile of a typical coal utilization process, the mass fraction of the $47 \mathrm{VOC}$ species was calculated to investigate the VOC emission characteristics of typical coal utilization sources. The mass fractions of the $47 \mathrm{VOC}$ species emissions from each coal utilization source are presented in Fig. 1, and the VOC group weight percentages from emission sources are shown in Fig. 2.

\subsubsection{Power plant}

The main VOC species in the flue gas of power plants were 1-butene, propane, isobutane, acetylene, toluene, and styrene. 1-Butene was the largest contributing VOC species of Power

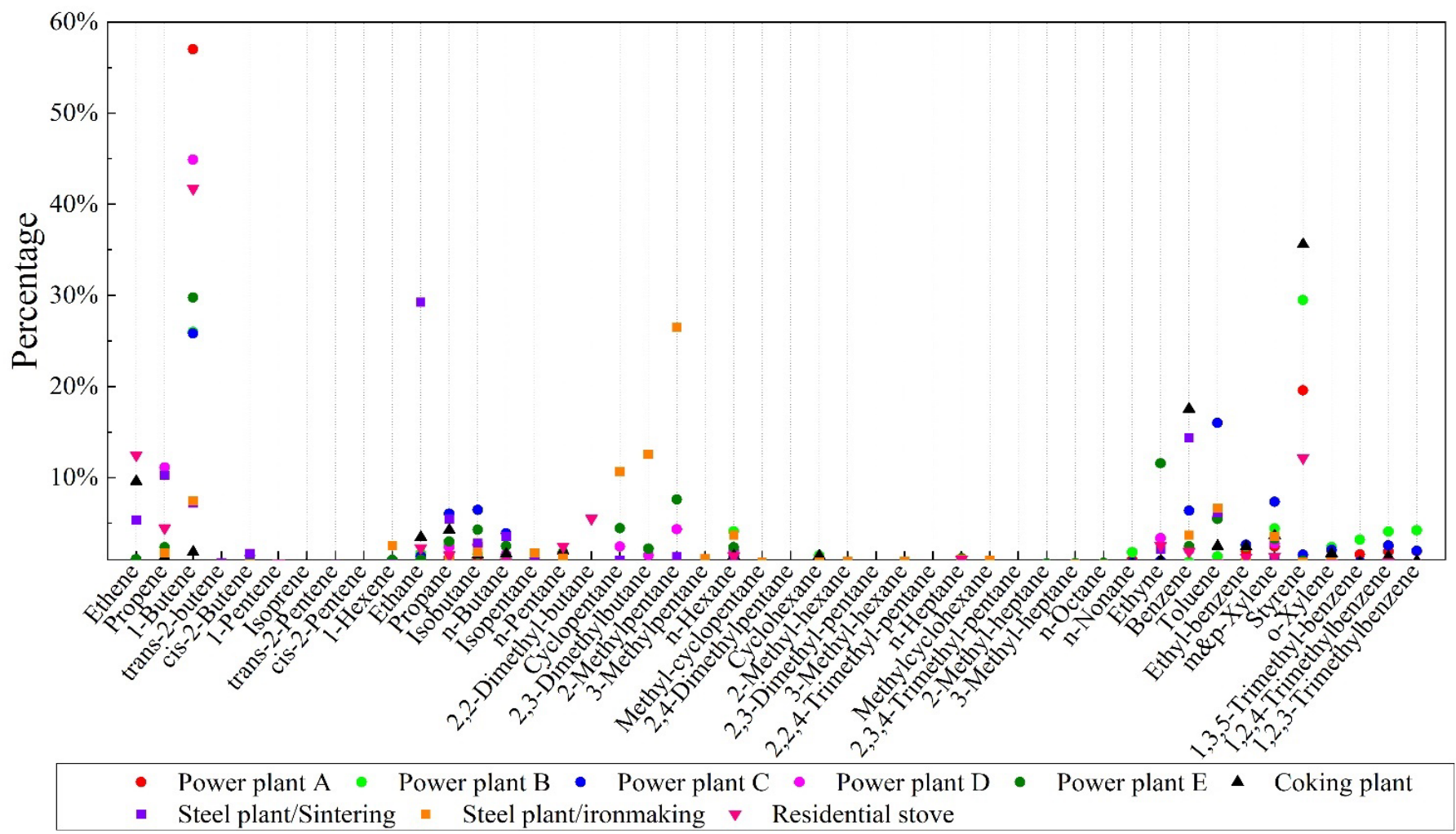

Fig. 1. VOC source profiles of coking plant, steel plants, power plants and residential stoves.

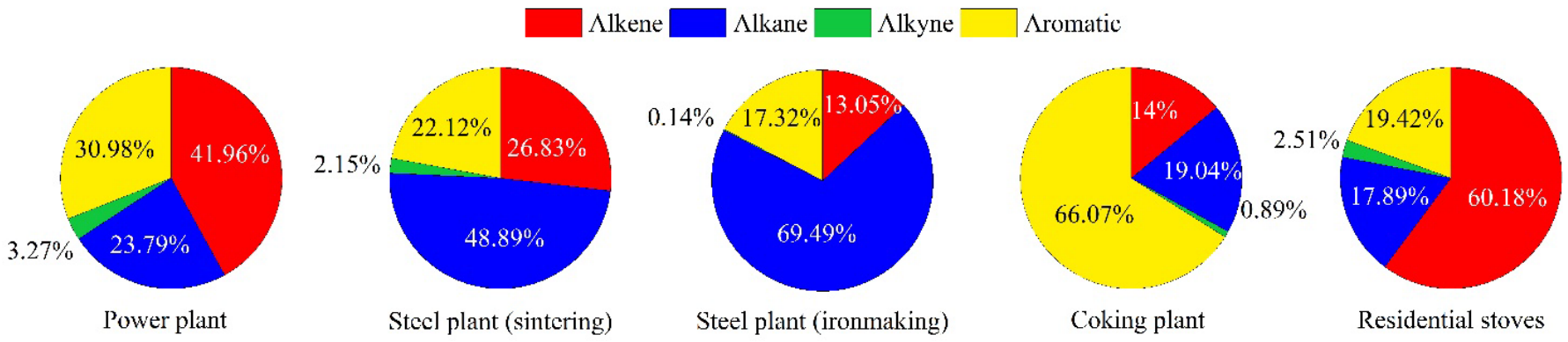

Fig. 2. VOC group weight percentages from different emission sources. 
Plants A, C, D, and $E$ (weight fractions of $57.0 \%, 25.8 \%, 44.9 \%$, and $29.8 \%$, respectively), and the second-largest contributor in Plant B (with $26.0 \%$ of weight fraction). As shown in Fig. S1, the high weight percentage of 1-butene in this study was consistent with the previous results from a coalfired power plant in Shanxi Province (Yan et al., 2016), but much higher than that in Liaoning (Shi et al., 2015) and Hebei Province (Li et al., 2018), with the values of $1.4 \%$ and $0.6 \%$, respectively. The characteristics of some VOC species showed the obvious differences between the two types of coal combustion technology. The weight fractions of the major VOC species propylene, propane, acetylene, benzene, and toluene from power plants with circulating fluidized bed boilers were apparently higher than those from pulverized coal-fired boilers; these results were the same as the findings observed in circulating fluidized bed boilers and pulverized coal-fired boilers in power plants in Hebei Province (Table S1; Li et al., 2018). In addition, due to the different sources of coal, the percentages of some VOC species showed large differences between Power Plants A and B (with coal sourced from the middle area of Shanxi) and Power Plants $C, D$, and $E$ (with coal sourced from the southern area of Shanxi). For instance, the weight fraction of styrene was significantly higher in Power Plants $A$ and $B(19.6 \%$ and $29.5 \%$, respectively), while the percentages of styrene in Power Plants C, D, and E were all less than $1.0 \%$. The weight fractions of benzene in Power Plants $A$ and $B$ were less than 1.0\%, which were lower than those of Power Plants C, D, and E (6.4\%, 2.1\%, and $2.5 \%$, respectively). The same situation was also observed for toluene, with toluene percentages of $0.5 \%$ and $1.4 \%$ for Power Plant $A$ and $B$, respectively, and $16.0 \%, 5.6 \%$, and $5.5 \%$ for Power Plants $C, D$, and $E$, respectively.

The major VOC groups of the three power plants with pulverized coal-fired boilers $(A, B$, and C) were alkenes and aromatics, accounting for $89.7 \%, 79.9 \%$, and $71.0 \%$, respectively. The main VOC groups of the two power plants with a circulating fluidized bed boiler ( $C$ and $D$ ) were alkenes and alkanes, in total accounting for $82.1 \%$ and $73.4 \%$, respectively. Alkyne from the three pulverized coal-fired boiler power plants were all less than $1 \%$, while those of two circulating fluidized bed boiler power plants were $11.6 \%$ and $3.4 \%$, respectively. According to SPECIATE 5.1 (U.S. EPA, 2020), aromatics were the main VOC group (64.8\%) from the stack flue gas of coalburning boiler electric generation, followed by alkanes (23.4\%) and alkenes (11.8\%). In comparison with the SPECIATE 5.1 data, we measured more alkenes and fewer aromatics in the coal-fired power plants in this study. In contrast, previous studies identified alkanes (Shi et al., 2015; Yan et al., 2016; Li et al., 2018) to be the largest VOC group in China. Therefore, these variations were likely caused by regional differences in coal combustion technology and coal quality. Our VOC source profile of power plants suggests that the VOC emission characteristics were largely affected by both coal utilization technology and coal sources.

\subsubsection{Steel plant}

The main VOC species in the flue gas of blast furnace ironmaking were 2-methylpentane, 2,3dimethylbutane, cyclopentane, 1-butene, and toluene, while the main VOC species in the sintering process were ethane, benzene, propylene, 1-butene, and propane. Benzene and toluene were also found to be the main species in the ironmaking process in Liaoning (Shi et al., 2015) and Taiwan (Tsai et al., 2008) steel plants, as shown in Fig. S2 and Table S2. The largest VOC species from the ironmaking process was 2-methylpentane, accounting for $26.5 \%$, but this species was not detected in the ironmaking process in Liaoning (Shi et al., 2015). As for the sintering process, the weight fraction of benzene was $14.4 \%$, which is consistent with the weight fraction of $16.1 \%$ reported by Miao (2017). Propylene (10.2\%), 1-butene (7.2\%), toluene (6.1\%), propane (5.4\%), ethylene $(5.3 \%)$, and $n$-butane $(3.5 \%)$ were the main species in the flue gas during sintering process. Among these species, benzene, 1-butene, $n$-butane, and toluene were also the most abundant species in the sintering process of Taiwan steel plants (Tsai et al., 2008). Notably, ethane was the largest VOC species in the flue gas of the sintering process in this study. According to SPECIATE 5.1 (U.S. EPA, 2020), ethane was also the major compound in the iron sintering process but was not detected in some steel plant studies (Tsai et al., 2008; Shi et al., 2015; Miao, 2017). Alkane was the most abundant VOC group emitted from both the blast furnace ironmaking process and sintering process, accounting for $69.5 \%$ and $48.9 \%$, respectively (Fig. 2). Previous studies identified aromatics to be the largest VOC group in Taiwan and Liaoning (Tsai et al., 2008; Shi et al., 2015). The weight fractions of aromatics, alkenes, and alkynes in the blast furnace ironmaking process were $17.3 \%, 13.1 \%$, and $0.1 \%$, respectively, and in the sintering process were $26.8 \%$, 
$22.1 \%$, and $2.2 \%$, respectively (Fig. 2). The different combustion technologies, combustion temperature, burning materials, and VOC source profiles in this study suggest that the emission characteristics of VOCs differed between the two coal utilization processes of steel plants.

\subsubsection{Coking plant}

The main VOC species from the coking plant were benzene, styrene, ethylene, ethane, and propane. Benzene was the largest VOC species contributor, contributing $32.1 \%$ to the total VOCs. As shown in Fig. S3 and Table S3, styrene was the main VOC species in the coking plant in this study (mass fraction of $35.6 \%$ ), which is contradictory to previous findings of similar studies that determined styrene mass fractions of less than 1\% (Jia et al., 2009; Shi et al., 2015; Wang et al., 2017; Li et al., 2018). Benzene was also the main VOC species in the coking plant, with a weight fraction of $17.6 \%$, and was also the main species (with a weight fraction of $20.5 \%$ ) in Hebei Province (Li et al., 2018). In other similar studies (Jia et al., 2009; Shi et al., 2015; Wang et al., 2017), the percentage of benzene was much lower than in this study, with $8.1 \%$ reported by Shi et al. (2015), 4.5\% reported by Wang et al. (2017), and $0.2 \%$ and $0.4 \%$ reported by Jia et al. (2009). The weight fraction of ethene was $9.6 \%$ and was identified as the main VOC emission species from coking plants in other studies (Jia et al., 2009; Wang et al., 2017; Li et al., 2018). The weight fraction of ethane was only $3.4 \%$ in this study and less than $0.1 \%$ in Liaoning Province (Shi et al., 2015), but its value in other studies ranged from $18.5 \%$ to $28.9 \%$ (Jia et al., 2009; Wang et al., 2017; Li et al., 2018). The VOC characteristics in coking plants showed large differences between different regions due to the different coke oven models, materials, and coking temperatures applied. Among the species, aromatics were the largest contributors (66.4\%), followed by alkanes $(19.1 \%)$, alkenes $(14.1 \%)$, and alkynes $(0.9 \%)$.

\subsubsection{Residential stove}

In this study, 1-butene was the largest contributor to the total VOC emissions from residential coal-burning stoves, accounting for 44.9\%. 1-Butene was also the main VOC species identified in three different types of coal (raw anthracite, raw bituminous coal, and briquette of bituminous coal) (Liu et al., 2008a). The second-largest species in the stack gas of residential stoves was ethylene, accounting for $12.5 \%$, which was consistent with the results of other residential coal utilization studies, including $12.6 \%$ from Liu et al. (2008a) and 14.4\% from Liu et al. (2017). As shown in Fig. S4 and Table S4, a higher weight fraction of ethylene was also found in many previous residential coal usage studies (Tsai et al., 2003; Wang et al., 2013; Mo et al., 2016). In addition, the abundant VOC species of residential coal usage included styrene (12.6\%), 2,2-dimethyl butane $(5.5 \%)$, propylene $(4.5 \%)$, acetylene $(2.5 \%), n$-pentane $(2.5 \%)$, ethane $(2.3 \%)$, and benzene (1.9\%). Among these species, ethane, acetylene, propylene, and benzene have also been observed as the dominant species in many similar studies (Tsai et al., 2003; Liu et al., 2008a; Wang et al., 2013; Mo et al., 2016; Liu et al., 2017). Alkenes were the major VOC group in the flue gas of residential coal-burning stoves, followed by aromatics, alkanes, and alkynes, accounting for $60.1 \%, 19.5 \%, 17.9 \%$, and $2.5 \%$, respectively. Some previous studies also found alkenes to be the most abundant VOC group in residential coal usage (Wang et al., 2013; Mo et al., 2016), while Liu et al. (2017) found alkanes to be the largest VOC group in residential coal usage, regardless of smoldering or flaming combustion processes. The results from Taiwan also showed that alkanes were the largest VOC group from residential coal usage (Tsai et al., 2003).

\subsection{BTEX Ratio}

The ratios of two particular VOC species of benzene series (benzene, toluene, ethylbenzene, and xylene) have been widely used to investigate the emission characteristics of VOCs. In a previous study, B/T ratios higher than 1 were considered to be associated with coal-fired industrial emissions (Santos et al., 2004; Liu et al., 2008a). As shown in Table 2, the average B/T ratios in this study varied greatly in different coal utilization processes. The $\mathrm{B} / \mathrm{T}$ ratios in the power plant, sintering process of the steel plant, ironmaking process of the steel plant, coking plant, and residential stove were $0.47,2.34,0.56,7.03$, and 2.99 , respectively.

The $\mathrm{B} / \mathrm{T}$ ratios of five power plants ranged from 0.37 to 0.57 , which are higher than those of coal-fired power stations in Liaoning Province (Shi et al., 2015) and lower than those of power 
plants in Korea (Pudasainee et al., 2010), Brazil (Santos et al., 2004) and northern China (Yan et al., 2016). As shown in Table 2, the BTEX ratios showed large differences between power plants that used different sources of coal. For instance, the B/E ratios were between 2.14 and 2.43 for Power Plants C, D, and E, and only 0.16 and 0.31 for the other two power plants. The B/E ratios were 0.29 and 0.55 for Power Plants $A$ and $B$, respectively, and $>5$ for Power Plants $C, D$, and $E$. The same observations were also noted for the $B / T, T / E, T / X$, and $E / X$ ratios. Dagaut and Cathonnet (1998) showed that benzene and toluene were formed from low-molecular unsaturated hydrocarbons, which cracked macromolecules in the fuel, while xylene was directly formed from the incomplete combustion of macromolecules; therefore, the different coal qualities may have caused the observed differences in BTEX values. The B/T ratio of steel plants in our studies was 2.34 for the sintering process and 0.56 for the blast furnace ironmaking process, which are within the range of previous studies. As previously mentioned, the contribution rates of benzene to VOC concentrations in the stack gases of coking plants were much higher than those of other coalfired industries. The $\mathrm{B} / \mathrm{T}$ ratios of coking plants in this study were 7.03 compared with $0.14-1.28$ in other studies. The $B / T$ ratio of residential coal-burning stoves was 2.99 , which is consistent with the $B / T$ ratio (2.86) of residential coal usage determined by Wang et al. (2013). Compared with previous studies, the $B / T$ ratio of residential coal usage in this study was lower than that reported by Mo et al. $(3.47 ; 2016)$ but higher than that reported in other similar studies (Tsai et al., 2003; Liu et al., 2008a; Liu et al., 2017).

Table 2. BTEX ratios from different VOC emission sources.

\begin{tabular}{|c|c|c|c|c|c|c|c|c|}
\hline Source & Reference & $\mathrm{B}: \mathrm{T}$ & $\mathrm{B}: \mathrm{E}$ & $\mathrm{B}: \mathrm{X}$ & $\mathrm{T}: \mathrm{E}$ & $\mathrm{T}: \mathrm{X}$ & $\mathrm{E}: \mathrm{X}$ & Notes \\
\hline \multirow[t]{11}{*}{ Power plants } & $\begin{array}{l}\text { Power Plant A (this } \\
\text { study) }\end{array}$ & 0.57 & 0.16 & 0.08 & 0.29 & 0.14 & 0.49 & Pulverized coal-fired boiler \\
\hline & Power Plant B & 0.57 & 0.31 & 0.11 & 0.55 & 0.20 & 0.36 & Pulverized coal-fired boiler \\
\hline & Power Plant C & 0.40 & 2.43 & 0.68 & 6.09 & 1.70 & 0.28 & Pulverized coal-fired boiler \\
\hline & Power Plant D & 0.37 & 2.14 & 0.60 & 5.84 & 1.64 & 0.28 & Circulating fluidized bed boiler \\
\hline & Power Plant E & 0.45 & 2.36 & 0.61 & 5.20 & 1.34 & 0.26 & Circulating fluidized bed boiler \\
\hline & Pudasainee et al. & 1.73 & & & & & & Anthracite coal \\
\hline & (2010) & 0.80 & & & & & & Bituminous coal \\
\hline & Santos et al. (2004) & 8.53 & 33.06 & 55.71 & 3.88 & 6.53 & 1.69 & \\
\hline & Shi et al. (2015) & 0.17 & 2.75 & 1.20 & 15.80 & 6.88 & 0.44 & Pulverized coal-fired boiler \\
\hline & Yan et al. (2016) & 1.02 & 0.19 & 0.11 & 0.19 & 0.11 & 0.58 & Anthracite coal \\
\hline & Li et al. (2018) & 2.84 & 5.16 & 3.30 & 1.81 & 1.16 & 0.64 & \\
\hline \multirow[t]{5}{*}{ Steel plants } & This study & 2.34 & 60.53 & 12.83 & 25.90 & 5.49 & 0.21 & Sintering \\
\hline & & 0.56 & 3.61 & 0.86 & 6.47 & 1.54 & 0.24 & Ironmaking process \\
\hline & Tsai et al. (2008) & 0.25 & 1.86 & 0.89 & 7.52 & 3.62 & 0.48 & Sintering \\
\hline & Miao (2017) & 3.61 & 12.15 & 5.77 & 3.37 & 1.60 & 0.48 & Sintering \\
\hline & Shi et al. (2015) & 0.16 & 3.29 & 1.37 & 20.56 & 8.59 & 0.42 & \\
\hline \multirow[t]{9}{*}{ Coking plants } & This study & 7.03 & 7.17 & 3.29 & 1.02 & 0.47 & 0.46 & Machine coke oven \\
\hline & He et al. (2005) & 0.22 & 1.73 & 0.32 & 8.01 & 1.45 & 5.46 & Traditional coke oven \\
\hline & & 0.48 & 4.18 & 1.22 & 8.65 & 2.53 & 3.41 & Machine coke oven \\
\hline & Tsai et al. (2008) & 0.14 & 0.91 & 0.50 & 6.66 & 3.67 & 0.55 & Cokemaking \\
\hline & Jia et al. (2009) & 1.27 & 5.00 & 0.79 & 3.93 & 0.62 & 0.16 & 58-II type \\
\hline & & 1.28 & 15.95 & 1.75 & 12.42 & 1.36 & 0.11 & JN43-80 type \\
\hline & Shi et al. (2015) & 0.29 & 3.11 & 1.84 & 10.58 & 6.27 & 0.59 & \\
\hline & Li et al. (2018) & 3.06 & 68.33 & 9.76 & 22.33 & 3.19 & 0.14 & \\
\hline & Wang et al. (2017) & 1.28 & 9.49 & 1.26 & 7.40 & 0.99 & 0.13 & \\
\hline \multirow{7}{*}{$\begin{array}{l}\text { Residential } \\
\text { stove }\end{array}$} & This study & 2.99 & 1.48 & 0.92 & 0.50 & 0.31 & 0.62 & \\
\hline & Wang et al. (2013) & 2.86 & & & & & & \\
\hline & Liu et al. (2008) & 2.07 & & 5.68 & & 2.74 & & Raw anthracite \\
\hline & Liu et al. (2017) & 1.13 & & 3.72 & & 3.29 & & Smoldering combustion \\
\hline & & 1.91 & & & & & & Flaming combustion \\
\hline & Mo et al. (2016) & 3.47 & 13.57 & 6.25 & 3.91 & 1.80 & 0.46 & \\
\hline & Tsai et al. (2003) & 1.99 & 16.48 & 2.17 & 8.26 & 1.09 & 0.13 & \\
\hline
\end{tabular}


According to previous studies that assessed B/T ratios (Suthawaree et al., 2012), the B/T value can be used to distinguish traffic and non-traffic sources, with $\mathrm{B} / \mathrm{T}$ ratios of approximately 0.5 regarded as traffic sources. However, in this study, the $B / T$ ratios of the five power plants and ironmaking processes in steel plant blast furnaces were both approximately 0.5 , and the $B / T$ ratio of the coke oven in He et al. (2005) was 0.48 . Therefore, the use of the B/T ratio to identify vehicular emission sources may not be sufficient.

\subsection{OFP and SOA}

As VOCs are the main precursors of ozone formation and SOAs, we analyzed the OFP and SOA formation potential of selected VOC species to investigate the influence of typical coal utilization processes on atmospheric ozone (Yao et al., 2006; Liu et al., 2008a).

\subsubsection{OFP}

The major ozone-forming species in the power plants was 1-butene, contributing approximately $67.2 \%$ to the ozone formation. Alkenes and aromatics were the main contributors to ozone formation in this study, accounting for $72.6 \%$ and $20.0 \%$, respectively; they were also identified as major OFP VOC species in coal-burning power plants in previous studies (Shi et al., 2015; Yan et al., 2016). Among the five power plants, the OFP results differed between power plants with different coal utilization technologies. According to Fig. 3, no alkanes or alkynes were observed in the top 10 OFPS of VOC species in all three coal-fired power plants with pulverized coal-fired boilers, while 2-methylpentane and cyclopentane were the main OFP VOC species in both power plants that use circulating fluidized beds. In coking plants, the two most abundant oxygenforming species were ethylene and styrene, contributing $46.2 \%$ to the total ozone formation. Although ethylene only accounted for $9.6 \%$ of the total VOC emissions from coking plants, the OFP of ethylene contributed $27.0 \%$ to ozone formation. In comparison, the OFP of alkenes and aromatics accounted for $37.2 \%$ and $47.0 \%$, respectively. No alkanes or alkynes were observed in the top 10 OFPs of VOC species in the coking plant. As for steel plants, propylene, 1-butene, toluene, cis-2-butene, and $m$-xylene were the main species contributing to the OFP in both the blast furnace ironmaking process and the sintering process. Notably, although alkenes accounted for only $22.8 \%$ and $9.9 \%$ of the total VOC emissions from the blast furnace ironmaking process in
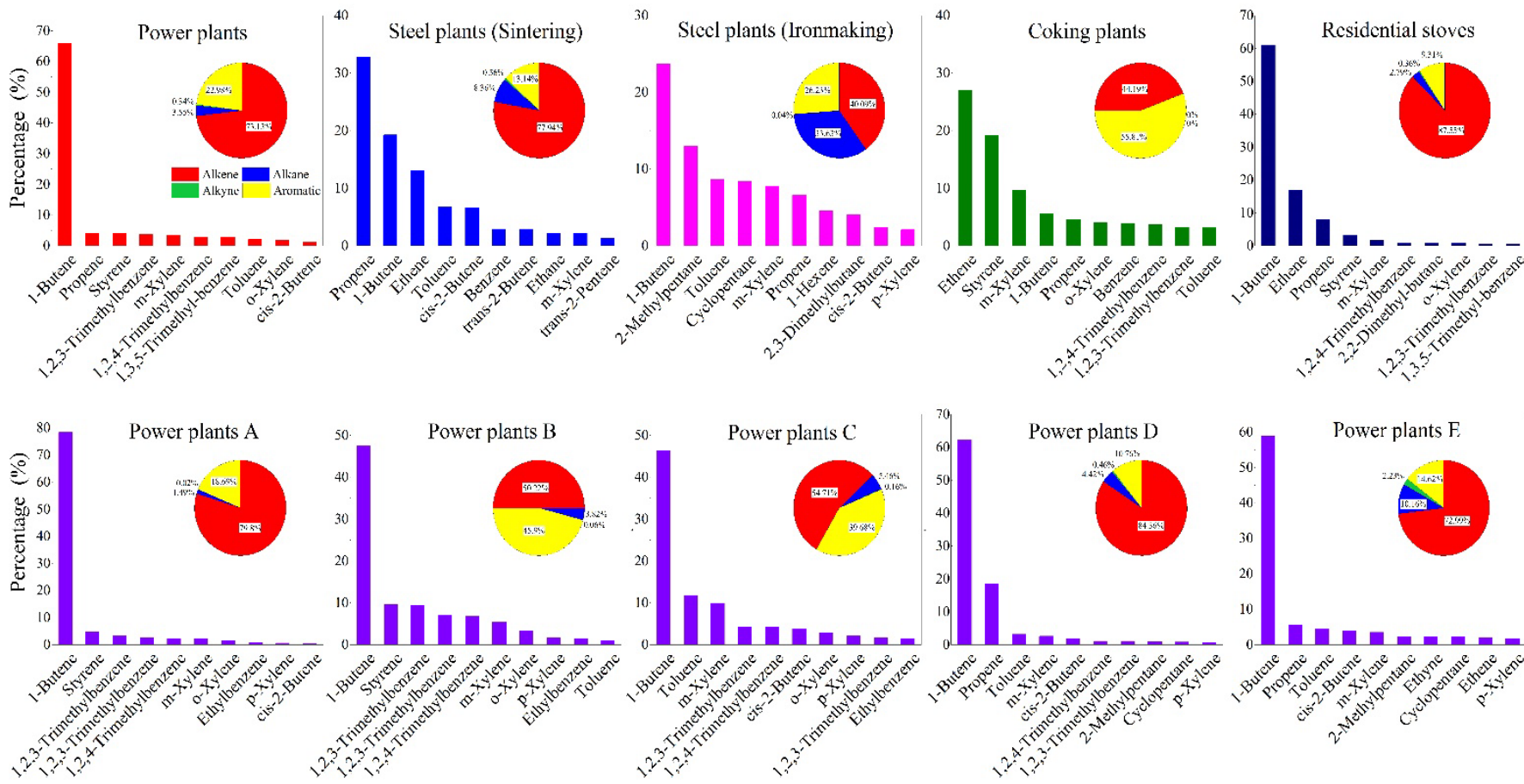

Fig. 3. Contribution of VOC groups and the top 10 VOC species to the OFP in coking plants, steel plants, power plants, and residential stoves. 
Table 3. Weight percentages of SOA formation for VOC species.

\begin{tabular}{|c|c|c|c|c|c|c|c|c|c|c|}
\hline \multirow[b]{2}{*}{ VOC species } & \multirow{2}{*}{$\begin{array}{l}\text { FAC } \\
(\%)\end{array}$} & \multicolumn{9}{|c|}{ CONTRIBUTION RATE (\%) } \\
\hline & & $\begin{array}{l}\text { Plant } \\
\text { A }\end{array}$ & $\begin{array}{l}\text { Plant } \\
\text { B }\end{array}$ & $\begin{array}{l}\text { Plant } \\
\text { C }\end{array}$ & $\begin{array}{l}\text { Plant } \\
\text { D }\end{array}$ & $\begin{array}{l}\text { Plant } \\
\text { E }\end{array}$ & $\begin{array}{l}\text { Sintering } \\
\text { furnace }\end{array}$ & $\begin{array}{l}\text { Blast } \\
\text { furnace }\end{array}$ & $\begin{array}{l}\text { Coking } \\
\text { plant }\end{array}$ & $\begin{array}{l}\text { Residential } \\
\text { usage }\end{array}$ \\
\hline Isoprene & 2 & 0.23 & 0.54 & 0.02 & 0.12 & 0.20 & 0.12 & 0.03 & 0.98 & 0.84 \\
\hline Methylcyclopentane & 0.17 & 0.05 & 0.04 & 0.03 & 0.09 & 0.13 & 0.11 & 0.18 & 0.03 & 0.06 \\
\hline Cyclohexane & 0.17 & 0.19 & 0.29 & 0.02 & 0.08 & 0.12 & 0.15 & 0.18 & 0.17 & 0.07 \\
\hline$n$-Heptane & 0.06 & 0.06 & 0.03 & 0.02 & 0.08 & 0.12 & 0.02 & 0.09 & 0.12 & 0.22 \\
\hline Methylcyclohexane & 2.7 & 0.46 & 0.51 & 0.91 & 2.01 & 3.20 & 1.69 & 3.57 & 0.22 & 0.25 \\
\hline 2-Methylheptane & 0.5 & 0.14 & 0.13 & 0.12 & 0.35 & 0.51 & 0.04 & 0.30 & 0.03 & 0.04 \\
\hline 3-Methylheptane & 0.5 & 0.12 & 0.11 & 0.09 & 0.31 & 0.52 & 0.07 & 0.35 & 0.03 & 0.05 \\
\hline$n$-Octane & 0.06 & 0.04 & 0.04 & 0.02 & 0.04 & 0.07 & 0.01 & 0.04 & 0.01 & 0.06 \\
\hline$n$-Nonane & 1.5 & 3.22 & 3.14 & 0.62 & 1.08 & 0.81 & 0.09 & 0.65 & 0.80 & 2.25 \\
\hline Benzene & 2 & 1.31 & 1.77 & 7.50 & 6.79 & 8.09 & 40.97 & 10.22 & 36.50 & 13.30 \\
\hline Toluene & 5.4 & 6.18 & 8.43 & 50.84 & 50.03 & 48.11 & 47.33 & 49.43 & 14.02 & 12.00 \\
\hline Ethylbenzene & 5.4 & 21.52 & 15.28 & 8.34 & 8.57 & 9.24 & 1.83 & 7.64 & 13.74 & 24.23 \\
\hline$m$-Xylene & 4.7 & 16.56 & 15.88 & 15.07 & 14.57 & 13.65 & 5.38 & 15.89 & 15.59 & 20.54 \\
\hline$p$-Xylene & 1.6 & 2.59 & 2.73 & 1.80 & 2.35 & 3.93 & 0.42 & 2.42 & 0.78 & 0.80 \\
\hline o-Xylene & 5 & 14.72 & 13.65 & 6.11 & 5.35 & 6.40 & 0.94 & 5.16 & 8.75 & 11.92 \\
\hline 1,3,5-Trimethylbenzene & 2.9 & 9.69 & 10.63 & 1.31 & 1.44 & 1.07 & 0.19 & 0.84 & 2.18 & 3.65 \\
\hline 1,2,4-Trimethylbenzene & 2 & 8.02 & 9.37 & 2.99 & 2.90 & 1.48 & 0.25 & 1.34 & 2.84 & 5.13 \\
\hline 1,2,3-Trimethylbenzene & 3.6 & 14.91 & 17.42 & 4.17 & 3.84 & 2.35 & 0.39 & 1.67 & 3.20 & 4.57 \\
\hline
\end{tabular}

steel plants, the OFP of alkenes in the top 10 VOC species contributed $76.0 \%$ and $37.2 \%$ to ozone formation in the two processes. In contrast, the alkane contribution rate to VOC emissions from the two steel plant processes was $41.0 \%$ and $55.3 \%$, respectively, while the contribution of alkanes to ozone formation declined to $2.3 \%$ and $25.4 \%$, respectively. This suggests that the chemical reactivity of alkenes during ozone formation is much higher than that of alkanes. Aromatics from steel plants contributed $11.7 \%$ and $18.6 \%$ to the OFP in the two processes, respectively. The main contributing species to the OFP in residential coal usage were 1-butene, ethylene, and propylene, accounting for $61.0 \%, 16.9 \%$, and $7.9 \%$, respectively. Moreover, alkenes had the highest contribution rate to ozone formation at $68.7 \%$, followed by aromatics $(8.0 \%)$ and alkanes $(1.0 \%)$.

The contribution of different VOC species to ozone formation was influenced by both their concentration mass fractions and their maximum incremental reactivity coefficient value. Lowconcentration mass fraction VOC species may have a high contribution rate to ozone formation; therefore, both high-concentration mass fractions and high-OFP VOC species should be considered for the effective control of VOC pollution. Our results showed that alkenes were the dominant oxygen-forming VOC group in the four types of coal utilization processes, and aromatics were the major ozone-forming VOC group in coal-fired steel plants and power plants. Alkenes were the largest contributor to the OFP in all five power plants, with an alkene percentage of more than $50 \%$, and the major VOC species were similar among power plants. To improve the effectiveness of ambient ozone control measures, policymaking agencies should focus more on alkenes and aromatics when establishing related policies for controlling VOCs.

\subsubsection{SOA}

VOCs also chemically react with atmospheric oxidants $\left(\mathrm{OH}, \mathrm{NO}_{3}\right.$, and $\left.\mathrm{O}_{3}\right)$ in the atmosphere, and the oxidation products subsequently form SOA, which influences atmospheric visibility. The potential formation of SOA in this study was estimated using fractional aerosol coefficients (Grosjean, 1992). According to Table 3, the top 5 VOC species contributing to the total SOA formation in the flue gases of coal utilization processes are all in the benzene series. In the four types of coal utilization processes, aromatics accounted for more than $94.0 \%$ of the total SOA formation. $n$-Nonane was the major VOC species contributing to SOA formation from power plants and residential stoves, and methylcyclohexane was the major VOC species of SOA formation from power plants and steel plants. 
We evaluated the emission characteristics, OFP-related chemical reactivity, and SOA formation potential of VOCs originating from four types of coal-utilizing sources in northern China, namely, steel plants, power plants, coking plants, and residential stoves. The VOC profiles significantly varied between different the coal utilization processes. Both the coal source and the combustion technology influenced the profiles for the five studied power plants. However, based on the BTEX ratios, the former factor played a larger role in shaping the BTEX emissions. Furthermore, at the steel plants, sintering generated alkanes and alkenes as the predominant VOC species $(48.9 \%$ and $26.8 \%$ of the total VOCs, respectively), but blast furnace ironmaking generated alkanes and aromatics $(69.5 \%$ and $17.3 \%)$. We also found far higher $\mathrm{B} / \mathrm{T}$ ratios for coking plants than those previously reported but lower ratios for power plants $(0.37-0.57)$ than the one commonly recognized (1.0). As we collected all of our samples from Shanxi Province, subsequent research should assess whether these values are location-specific.

Additionally, we identified the largest contributors to the OFP of the emitted VOCs as alkenes for the steel plants, power plants, and residential stoves (59.0-87.6\%) but as aromatics for the coking plants (55.8\%). Notably, alkenes accounted for $33.6 \%$ of the total OFP at the steel plants (ironmaking process) but only $0-8.4 \%$ for the other sources. Lastly, above $94.0 \%$ of the SOA formation was attributable to aromatics across all of the studied sources.

\section{ACKNOWLEDGMENTS}

This work was supported by grants from the National Key R\&D Program of China (No. 2019YFC0214200), the National Natural Science Foundation of China (NSFC; No. 21976053), the Fundamental Research Funds for the Central Universities (Nos. 2019QN089 and 2018ZD12), Key Project of Heavy Air Pollution Cause and Control (No. DQGG-05-13) and Hunan Provincial Key Research and Development Program (2018SK2039).

\section{DISCLAIMER}

The authors declare no competing financial interests.

\section{SUPPLEMENTARY MATERIAL}

Supplementary material for this article can be found in the online version at https://doi. org/10.4209/aaqr.210050

\section{REFERENCES}

Carter, W.P.L (2010). Updated maximum incremental reactivity scale and hydrocarbon bin reactivities for regulatory applications. California Air Resources Board Contract 07-339.

Cetin, E., Odabasi, M., Seyfioglu, R. (2003). Ambient volatile organic compound (VOC) concentrations around a petrochemical complex and a petroleum refinery. Sci. Total Environ. 312, 103-112. https://doi.org/10.1016/S0048-9697(03)00197-9

Chen, C.L., Fang, H.Y., Shu, C.M. (2006). Mapping and profile of emission sources for airborne volatile organic compounds from process regions at a petrochemical plant in Kaohsiung, Taiwan. J. Air Waste Manage. Assoc. 56, 824-833. https://doi.org/10.1080/10473289.2006.10 464486

Cheng, C.H., Su, L.Y., Wang, H.L., Huang, C., Li, L., Zhou, M., Qiao, Y.Z., Chen, Y.R., Chen, M.H., Huang, H.Y., Zhang, G.F. (2012). Variation and key reactive species of ambient VOCs in the urban area of Shanghai, China. Acta Sci. Circumst. 32, 367-376. https://doi.org/10.13671/j.hjkxxb.20 12.02.022

China Coking Industry Association (2019). Forty years of development of coking industry reform 
and opening up in China. China Coking Industry Association, China.

China Electricity Council (2020). China Electric Power Yearbook 2020, China Statistics Press, China.

Dagaut, P., Cathonnet, M. (1998). A comparative study of the kinetics of benzene formation from unsaturated $C_{2}$ to $C_{4}$ hydrocarbons. Combust. Flame 113, 620-623. https://doi.org/10.1016/s0 010-2180(97)00244-7

Dai, L. (2017). The perennity of implementation of coal control strategy. Energy Conservation and Environmental Protection, 29-30. https://doi.org/CNKI:SUN:BJJN.0.2017-01-013

Evtyugina, M., Calvo, A.I., Nunes, T., Alves, C., Fernandes, A.P., Tarelho, L., Vicente, A., Pio, C. (2013). VOC emissions of smouldering combustion from Mediterranean wildfires in central Portugal. Atmos. Environ. 64, 339-348. https://doi.org/10.1016/j.atmosenv.2012.10.001

Fernández-Martínez, G., López-Mahía, P., Muniategui-Lorenzo, S., Prada-Rodríguez, D., FernándezFernández, E. (2001). Distribution of volatile organic compounds during the combustion process in coal-fired power stations. Atmos. Environ. 35, 5823-5831. https://doi.org/10.1016/s 1352-2310(01)00282-5

Grosjean, D. (1992). In situ organic aerosol formation during a smog episode: Estimated production and chemical functionality. Atmos. Environ. 26, 953-963. https://doi.org/10.1016/0960-1686 (92)90027-i

He, Q.S., Wang, X.M., Zhao, L.R., Sheng, G.Y., Fu, J.M. (2005). Preliminary study on profiles of VOCs emitted from coking. Environ. Monit. China 21, 61-65. https://doi.org/10.3969/j.issn.10026002.2005.01.019 (in Chinese)

$\mathrm{Hu}, \mathrm{X}$. (2017). Analysis on the Emission Characteristics and Control Technologies Application of Volatile Organic Compounds from Industries in Qinhuangdao. Tianjin University.

Huang, H., Sha, Q., Zhu, M., Wang, Y., Lu, M., Zhanfg, X., Mingshuang, T., Zhijiong, H., Shi, B., Bai, L., Huang, J., Yan, M., Zheng, J. (2020). Evolution of emission characteristics and species of industrial VOCs emission in Pearl River Delta Region, 2010 2017. China Environ. Sci. 40, 4-14. https://doi.org/10.19674/j.cnki.issn1000-6923.20200915.001 (in Chinese)

James, J.S., Michael, J.K., Glen, R.C., Bernd, R.T.S. (2001). Measurement of emissions from air pollution sources. 3. $\mathrm{C}_{1}-\mathrm{C}_{29}$ organic compounds from fireplace combustion of wood. Environ Sci. Technol. 35, 1716-1728. https://doi.org/10.1021/es001331e

Jia, J.H., Huang, C., Chen, C.H., Chen, M.H., Wang, L.H., Shao, M., Dong, Y.L., Dai, P., Xie, S.C., Lu, J., Huang, H.Y. (2009). Emission characterization and ambient chemical reactivity of volatile organic compounds (VOCs) from coking processes. Acta Sci. Circumst. 29, 905-912. https://doi.org/10.13671/j.hjkxxb.2009.05.030 (in Chinese)

Jumpponen, M., Roenkkoemaeki, H., Pasanen, P., Laitinen, J. (2013). Occupational exposure to gases, polycyclic aromatic hydrocarbons and volatile organic compounds in biomass-fired power plants. Chemosphere 90, 1289-1293. https://doi.org/10.1016/j.chemosphere.2012.10.001

Kawashima, H., Minami, S., Hanai, Y., Fushimi, A. (2006). Volatile organic compound emission factors from roadside measurements. Atmos. Environ. 40, 2301-2312. https://doi.org/10.1016/ j.atmosenv.2005.11.044

Li, G.H., Wei, W., Cheng, S.Y., Wen, W., Wang, G. (2014). Emission characterization and ozone formation potential of VOCs during the coking process. J. Beijing Univ. Technol. 40, 91-99. https://doi.org/0254-0037(2014)01-0091-09 (in Chinese)

Li, G.H., Wei, W., Shao, X., Nie, L., Wang, H.L., Yan, X., Zhang, R. (2018). A comprehensive classification method for VOC emission sources to tackle air pollution based on VOC species reactivity and emission amounts. J. Environ. Sci. 67, 78-88. https://doi.org/10.1016/j.jes.2017. 08.003

Lin, T.Y., Sree, U., Tseng, S.H., Kong, H.C., Wu, C.H., Lo, J.G. (2004). Volatile organic compound concentrations in ambient air of Kaohsiung petroleum refinery in Taiwan. Atmos. Environ. 38, 4111-4122. https://doi.org/10.1016/j.atmosenv.2004.04.025

Liu, C.T., Zhang, C.L., Mu, Y.J., Liu, J.F., Zhang, Y.Y. (2017). Emission of volatile organic compounds from domestic coal stove with the actual alternation of flaming and smoldering combustion processes. Environ. Pollut. 221, 385-391. https://doi.org/10.1016/j.envpol.2016.11.089

Liu, Y., Shao, M., Fu, L., Lu, S., Zeng, L., Tang, D. (2008a). Source profiles of volatile organic compounds (VOCs) measured in China: Part I. Atmos. Environ. 42, 6247-6260. https://doi.org/ 10.1016/j.atmosenv.2008.01.070

Liu, Y., Shao, M., Lu, S., Chang, C.C., Wang, J.L., Fu, L. (2008b). Source apportionment of ambient 
volatile organic compounds in the Pearl River Delta, China: Part II. Atmos. Environ. 42, 62616274. https://doi.org/10.1016/j.atmosenv.2008.02.027

Lv, Z.F., Hao, J.M., Chun, D.J., Li, J.H. (2009). Estimate of the formation potential of secondary organic aerosol in Beijing summertime. Environ. Sci. 30, 969-975. (in Chinese)

Ma, Z.Z., Li, Z., Jiang, J.K., Ye, Z.X., Deng, J.G., Duan, L. (2015). Characteristics of water-soluble inorganic ions in $\mathrm{PM}_{2.5}$ emitted from coal fired power plants. Environ. Sci. 36, 2361-2366. https://doi.org/10.13227/j.hjkx.2015.03.047 (in Chinese)

Miao, P.R. (2017). Research on VOCs emission characteristics in sintering process. Environ. Dev. 29, 79-86. https://doi.org/10.16647/j.cnki.cn15-1369/X.2017.02.015 (in Chinese)

Ministry of Ecological Environment (2020). State of the environment bulletin of China 2019. Ministry of Ecological Environment, China.

Mo, Z., Shao, M., Lu, S.H. (2014). Emission characteristics of volatile organic compounds (VOCs) from typical solvent use factories in Beijing, China. Acta Sci. Circumst. 34, 2179-2189. https://doi.org/10.1111/j.1600-0609.2007.00986.x (in Chinese)

Mo, Z., Lu, S.H., Li, Y., Shao, M., Qu, H. (2015). Emission characteristics of volatile organic compounds (VOCs) from typical solvent use factories in Beijing. China Environ. Sci. 35, 374380. (in Chinese)

Mo, Z., Shao, M., Lu, S. (2016). Compilation of a source profile database for hydrocarbon and OVOC emissions in China. Atmos. Environ. 143, 209-217. https://doi.org/10.1016/j.atmosenv. 2016.08.025

National Bureau of Statistics (2019). China Energy Statistics Yearbook 2019. China Statistical Press, China.

Niedojadlo, A., Becker, K.H., Kurtenbach, R., Wiesen, P. (2007). The contribution of traffic and solvent use to the total NMVOC emission in a German city derived from measurements and CMB modelling. Atmos. Environ. 41, 7108-7126. https://doi.org/10.1016/j.atmosenv.2007.04. 056

Olson, D.A., Hammond, D.M., Seila, R.L., Burke, J.M., Norris, G.A. (2009). Spatial gradients and source apportionment of volatile organic compounds near roadways. Atmos. Environ. 43, 5647-5653. https://doi.org/10.1016/j.atmosenv.2009.07.065

Pudasainee, D., Kim, J.H., Lee, S.H., Park, J.M., Jang, H.N., Song, G.J., Seo, Y.C. (2010). Hazardous air pollutants emission from coal and oil-fired power plants. Asia-Pac. J. Chem. Eng. 5, 299303. https://doi.org/10.1002/apj.268

Santos, M.C.Y., Azevedo, A.D., Neto, A.F.R. (2004). Atmospheric distribution of organic compounds from urban areas near a coal-fired power station. Atmos. Environ. 38, 1247-1257. https://doi.org/10.1016/j.atmosenv.2003.11.026

Shi, J., Deng, H., Bai, Z., Kong, S., Wang, X., Hao, J., Han, X., Ning, P. (2015). Emission and profile characteristic of volatile organic compounds emitted from coke production, iron smelt, heating station and power plant in Liaoning Province, China. Sci. Total Environ. 515-516, 101-108. https://doi.org/10.1016/j.scitotenv.2015.02.034

Suthawaree, J., Tajima, Y., Khunchornyakong, A., Kato, S., Sharp, A., Kajii, Y. (2012). Identification of volatile organic compounds in suburban Bangkok, Thailand and their potential for ozone formation. Atmos. Res. 104-105, 245-254. https://doi.org/10.1016/j.atmosres.2011.10.019

Tian, L. (2015). Research on VOCs Emission Characteristics and Ozone Generation Potential of Typical Industries in Beijing. Environmental Science and Engineering Beijing University of Technology, China.

Tsai, J.H., Lin, K.H., Chen, C.Y., Lai, N., Ma, S.Y., Chiang, H.L. (2008). Volatile organic compound constituents from an integrated iron and steel facility. J. Hazard. Mater. 157, 569-578. https://doi.org/10.1016/j.jhazmat.2008.01.022

Tsai, S.M., Zhang, J.J., Smith, K.R., Ma, Y., Rasmussen, R.A., Khalil, M.A.K. (2003). Characterization of non-methane hydrocarbons emitted from various cookstoves used in China. Environ. Sci. Technol. 37, 2869-2877. https://doi.org/10.1021/es026232a (in Chinese)

U.S. Environmental Protection Agency (U.S. EPA) (2020). SPECIATE 5.1. U.S. Environmental Protection Agency. https://www.epa.gov/air-emissions-modeling/speciate-4

Wang, D.S., Wang, M.R., Bai, X.F., Ding, H. (2016). The situation analysis of civil coal in the BeijingTianjin-Hebei region. Coal Qual. Technol. 46-49. https://doi.org/10.3969/j.issn.1007-7677.20 16.03.015 (in Chinese) 
Wang, L.H., Yang, Z.X., Jing, S.A. (2017). Volatile organic compounds( VOCs) source profiles of industrial processing and solvent use emissions: A review. Environ. Sci. 38, 2617-2628. https://doi.org/10.13227/j.hjkx.201611119 (in Chinese)

Wang, Q., Geng, C., Lu, S., Chen, W., Shao, M. (2013). Emission factors of gaseous carbonaceous species from residential combustion of coal and crop residue briquettes. Front. Environ. Sci. Eng. 7, 66-76. https://doi.org/10.1007/s11783-012-0428-5

$\mathrm{Wu}, \mathrm{R} ., \mathrm{Xie}, \mathrm{S}$. (2017). Spatial distribution of ozone formation in China derived from emissions of speciated volatile organic compounds. Environ. Sci. Technol. 51, 2574-2583. https://doi.org/10. 1021/acs.est.6b03634

Yan, Y., Yang, C., Peng, L., Li, R., Bai, H. (2016). Emission characteristics of volatile organic compounds from coal-, coal gangue-, and biomass-fired power plants in China. Atmos. Environ. 143, 261269. https://doi.org/10.1016/j.atmosenv.2016.08.052

Yao, L., Ge, M.F., Qiao, Z.M., Sun, Z., Wang, D.X. (2006). Progresses of tropospheric chemistry of volatile organic compounds. Chem. Online 69, 1-7.

Yao, S., Wei, W., Cheng, S.Y., Wang, G., Zhang, H.Y., Lei, C.G. (2016). Emission characteristics and chemical reactivity of volatile organic compounds from light-duty gasoline vehicles. China Environ. Sci. 36, 2923-2929. https://doi.org/10.3969/j.issn.1000-6923.2016.10.008 (in Chinese)

Yuan, B., Min, S., Lu, S., Wang, B. (2010). Source profiles of volatile organic compounds associated with solvent use in Beijing, China. Atmos. Environ. 44, 1919-1926. https://doi.org/10.1016/j.at mosenv.2010.02.014

Zhan, X. (2015). The Investigation on Chemical Compositions and Characteristics of Petrochemical Industrial VOCs Emission Sources in Tianjin City. University of Technology, China.

Zhang, J., Smith, K.R. (2007). Household air pollution from coal and biomass fuels in China: measurements, health impacts, and interventions. Environ. Health Perspect. 115, 848-855. https://doi.org/10.1289/ehp.9479

Zhang, Q.J., Wu, L., Liu, M.Y., fang, X.Z., Zhang, J., Mao, H.J., Shao, M., Lu, S.H. (2016). Pollution Characteristics And Health Risk Assessment Of Vocs From Vehicle Exhaust In Nanjing. China Environ. Sci. 36, 3118-3125. https://doi.org/CNKI:SUN:ZGHJ.0.2016-10-032 (in Chinese)

Zou, X.B., Zhou, X., Wu, Y.Q. (2013). Research progress of controlling volatile organic compounds in flue gas of coal-fired power plant. Environ. Sci. Surv. 32, 57-62. https://doi.org/10.3969/j.iss n.1673-9655.2013.06.016 (in Chinese) 